\title{
Pedro Poveda: assaigs i projectes pedagògics
}

\section{Margarita Bartolomé Pina*}

\section{Resum}

En aquest treball, presentem l'edició crítica de les obres pedagògiques de Pedro Poveda (18741936), recentment publicades. Oferim uns eixos fonamentals del seu treball pedagògic: A) La seva fe en l'educació com una eina extraordinàriament important per al canvi social i educatiu en períodes crítics de qualsevol societat. B) La unió d'esforços, la capacitat de respondre als reptes del moment amb creativitat i realisme des de moviments i grups, units per un projecte comú: la formació inicial i permanent d'educadors i educadores, i en especial aquells que s'orientaven a l'exercici professional en centres de titularitat pública. C) La seva proposta educativa, que arrelada profundament en un humanisme cristià, atraient i obert, pretenia potenciar el desenvolupament de la persona, des d'ambients humanitzadors, densos en relacions interpersonals, que poguessin afavorir l'estudi, el treball autònom, una vida plena de sentit i orientada al compromís social. D) La implicació de Poveda en la formació d'un collectiu emergent: les dones que, des de la seva vocació pedagògica, volien articular a la vida la fe i el progrés científic i cultural; el compromís professional i l'apertura a l'espai públic d'una societat en canvi amb l'estrena d'un nou rol i un nou estil.

\section{Paraules clau}

Pedro Poveda, moviments pedagògics, formació del professorat, ensenyament públic, humanisme cristià, ambient educatiu, amor pedagògic, fe-ciència, educació integral, formació de dones, compromís social.

Recepció original: 24 de febrer de 2017

Acceptació: 22 de març de 2017

Publicació: 19 de gener de 2018

\section{Introducció}

Possiblement, alguns dels meus collegues es poden sorprendre d'aquesta vesant menys coneguda del meu treball investigador. Perquè he volgut ficar-me en Pere Poveda i dedicar-me els darrers vuits anys a l'estudi de la seva producció pedagògica? Hauria de trobar les arrels d'aquest interès a l'àmbit familiar. La meva mare, una mestra apassionada i innovadora, es va formar a l'Acadèmia teresiana d'Alacant, i em va transmetre el seu entusiasme per la proposta educativa de Poveda. Poc a poc va néixer en mi la seva mateixa vocació pel magisteri que compartia també amb el meu pare, inspector d'ensenyament primari molts anys a la Guinea. Volia ser mestra i vaig estudiar per a mestra. És per això, per aquesta passió educativa, que, en acabar la carrera de Pedago-

(*) Catedràtica jubilada de la Universitat de Barcelona, la meva trajectòria professional ha estat associada des de 1964 a les àrees de Pedagogia Experimental i Pedagogia Diferencial (actualment MIDE). A partir de 1976 vaig interessar-me especialment per la recerca qualitativa orientada al canvi educatiu i social, lligada a una visió humanista de l'educació, orientació que es formularà més endavant. L'any 1973 vaig escriure Un pensamiento para la acción. El problema educativo en los textos de Pedro Poveda. Es tractava d'un primer estudi dels seus textos pedagògics. Aquesta aportació pedagògica sobre Pedro Poveda constituí un punt important de reflexió i anàlisi, que es va continuar en treballs posteriors $(1974,1979,1988,2008,2012,2015)$. He treballat els darrers vuit anys en l'edició crítica i estudi dels textos pedagògics d'aquest autor, recentment publicats sota el títol: Pedro Poveda, Obras II. Ensayos y proyectos pedagógicos (2016). Aquest escrit forma part de la presentació de Pedro Poveda. Ensayos y Proyectos pedagógicos, edició crítica i estudi, que va tenir lloc el 3 de novembre de 2016, un acte organitzat pels Departaments de Teoria i Historia de l'Educació i Mètodes d'Investigació i Diagnòstic en Educació de la Facultat d'Educació de la Universitat de Barcelona. Adreça electrònica: margaritabartolome@gmail.com 
gia, vaig combinar les primeres passes del treball universitari amb l'exercici del magisteri a primària, introduint noves metodologies educatives i dinàmiques d'aprenentatge.

No sempre podem triar a la Universitat la docència o recerca que voldríem impartir i/o treballar. Però el primer doctorat, coordinat per mi, del Departament de Pedagogia Experimental, Terapèutica i Orientació, es va anomenar «Educació i valors». Es plantejava a la vegada, a nivell teòric i empíric, un plantejament que ens ajudava a fer-nos preguntes sobre les persones i els seus valors proclamats i viscuts. De les seves respostes podíem comprendre quina educació és la que estàvem posant en pràctica i/o hauríem de promoure (Bartolomé, 1979, 1981).

Hi ha, per tant, una trajectòria viscuda que m'ha apropat, cada vegada més, a cercar i defensar valors i experiències educatives innovadores i, al mateix temps, engrescadores, per fer front a la incertesa, molt pròpia del nostre temps i avençar, amb esperança, cap a una humanitat més plena de sentit.

\section{Fe en l'educació}

Al llarg d'aquests vuit anys d'estudi dels textos de Poveda, vaig anar aprofundint com aquest home, al igual que molts dels seus contemporanis, creia en l'educació. Era, per a ells, un mitjà privilegiat per a la transformació personal i social. Per això calia repensar-la de nou. Imaginar noves formes de desenvolupar-la.

En realitat, foren temps de canvi els viscuts per l'autor. Crispats. Amb desigs, per part d'alguns, d'una societat distinta, incorporada al camí de la modernitat, emprès per altres nacions. Una societat més justa, volguda per altres, des de situacions insostenibles de desigualtat. Una societat que es preguntava si calia per tot això renunciar a les seves arrels cristianes, una identitat, molt sovint, defensada o qüestionada per uns o altres des de la desqualificació o la violència. Quins camins podien donar resposta a tantes necessitats, o fer front a tants reptes? Des d'on?

Recordem algunes veus. Per a Joaquín Costa, el problema d'Espanya, era un problema d'educació.

El problema de la regeneración de España es pedagógico tanto o más que económico y financiero y requiere una transformación profunda de la educación nacional (Costa, 1889, 1916, p. 71).

I Aniceto Sela, catedràtic de la Universitat de Oviedo i membre de la Institución Libre de Enseñanza, assenyalava els elements pedagògics que cal tenir en compte en «el problema más grave que hemos de resolver».

\footnotetext{
¿A qué hacernos ilusiones? No tenemos maestros, ni escuelas, ni normales, ni inspección, ni Institutos donde la educación de los alumnos no sea la última de las preocupaciones, ni Universidades y Escuelas Superiores en que la enseñanza deje de ser libresca, árida, distanciada de la realidad y de la vida. Formar profesores, construir escuelas, dotarlas de material y mobiliario, organizar una inspección competente, celosa y eficaz en todos los grados de la enseñanza (por hablar sólo de lo más urgente) parece aquí inasequible $y$, la verdad, mientras no se consiga, será inútil que pretendamos alternar con las naciones cultas (Sela, 1910, p. 9).
}

De manera semblant, considerava Ortega y Gasset un problema pedagògic, el problema espanyol. Recordem la seva coneguda afirmació:

Si educación es transformación de una realidad en el sentido de cierta idea mejor que poseemos, y la educación no ha de ser sino social, tendremos que la pedagogía es la ciencia de transformar sociedades. 
Antes llamamos a esto política; he aquí, pues, que la política se ha hecho para nosotros pedagogía y el problema social un problema pedagógico (Ortega y Gasset, 1910, p. 506).

Poveda com aquests pensadors, creia en l'educació. De fet, una de les primeres actuacions, poc temps després de la seva ordenació sacerdotal, va ser la construcció d'escoles per a la població marginada que vivia a les coves de Guadix. Era l'any 1902. Un any desprès, al sol-licitar el suport públic per al seu manteniment, argumentava així la seva petició:

El único medio para salvar aquellas pobres gentes... era fundar escuelas gratuitas donde se dispensara a las clases mencionadas la educación de la que están harto necesitadas... (Poveda, 1903, 2016, p. 36).

Tornarem després a Guadix, on Poveda descobrirà la seva vocació educadora. Però vull recollir, ara que hem deixat clar la fe en l'educació com un punt inicial per a comprendre tota la trajectòria vital d'aquest autor, unes paraules seves quan ja havia estudiat molt més a fons la qüestió educativa a Espanya:

Al problema pedagógico no se le ha concedido, en general, la importancia que tiene. Nuestro carácter, la manera que tenemos de mirar aún los asuntos de mayor transcendencia, lo que se llama nuestra idiosincrasia, la época, la necesidad de conocerlo todo, no profundizando en nada, la novedad del asunto en su aspecto científico y metódico, y algunas razones más, hicieron que, para no aparecer ante el mundo como hombres extraños al movimiento científico, nos incorporásemos a él de una manera contrahecha y superficial (...) Si nosotros hubiéramos tomado en serio la Pedagogía desde la época en que de ella se ocuparon seriamente las naciones que hoy nos la enseñan, tendríamos hoy, ¡cómo no!, hombres, libros, maestros, escuelas, métodos, material científico y todo lo que pueden prestar con honra para su pueblo, y provecho para sus habitantes, Alemania y Suiza, Inglaterra y Francia. ¿Y qué tenemos? Poco, muy poco de todo lo que da señales de vida pedagógica en una nación... (Poveda, 1912a, 2016, p. 507 i 509).

Aquest fragment d'un dels articles escrits per Poveda durant el darrers mesos de l'any 1912, recull de manera gràfica i crítica, aquesta importància que ell donava a l'educació i que suposava prendre-la de manera seriosa, a banda que aporta tots els mitjans i recursos necessaris per al seu desenvolupament.

I a aquesta tasca es va dedicar, en la mesura de les seves forces. L'atenció al moment present, li va portar a estudiar la manera com «se ocuparon los que hoy van a la cabeza de este movimiento pedagógico en formar a los maestros, para que ellos después formaran discípulos» (Poveda, 1912a, 2016, p. 508). Però, des de l'inici, entenia que no es pot plagiar cap projecte per interessant que sigui. Cal imaginar, això sí, des de la realitat concreta viscuda, avançar-se al present perquè el somni forma part indissoluble del

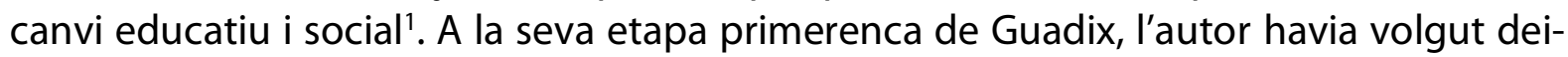
xar constància d'aquesta actitud davant la realitat: «No obstante lo consignado, tenemos mucha fe, mucha esperanza y no dejamos de soñar y hasta realizamos algunos sueños fiados en la Providencia» (Poveda, 1904, 2016, p. 45). Aquest és l'origen dels seus projectes pedagògics. Ell mateix justifica aquesta manera peculiar d'iniciar l'acció. En una entrevista sobre un dels seus projectes, construeix el següent diàleg entre un periodista il'autor:

\footnotetext{
-Luego ¿V. cree que haciendo es como más se adelanta?

-Lo creo y lo practico

-Entonces, ¿para qué el proyecto?
}

(1) Recordem la importància que es dóna a l'etapa del somni en els processos engegats dins de les comunitats d'aprenentatge actuals. 
-Porque, en general, no está reñido lo uno con lo otro: el proyectar no es obstáculo para el obrar, ni implica inacción, antes es camino para llegar a la ejecución» (Poveda, 1912b, 1989, p. 185-186)².

Al llarg de la seva vida, Poveda, humanista i pedagog, com el va definir la UNESCO l'any 1974, trobà, en primer lloc, situacions noves que reclamaven l'atenció i la recerca de camins per a respondre després a aquests reptes. Són aquests processos, expressats en els seus texts, els que ens poden ill.luminar en temps de canvi quan allò que es posa en joc és la construcció mateixa de la nostra societat i els processos de humanització que facilita o reprimeix.

\section{L’edició crítica}

Amb aquest convenciment, presento l'edició crítica dels texts pedagògics de Pedro Poveda. És el resultat d'uns anys de treball en equip ${ }^{3}$. Intentaré, encara que sigui molt breument, sintetitzar el contingut del llibre per animar a la seva lectura.

S'inicia el volum amb un estudi introductori en el que procurem desvetllar les línies fonaments del pensament pedagògic de l'autor. Partim del debat pedagògic cultural de l'Espanya de principis del segle XX i presentem la veu crítica de Poveda i el pla de regeneració educativa i cultural que planteja a través dels seus projectes. La seva proposta educativa que desenvolupem a continuació, parteix del profund humanisme cristià que constitueix les seves arrels. Hem intentat posar de relleu les aportacions més característiques de Poveda; la possible influència d'altres autors i corrents pedagògiques; la coherència que hem trobat en els seus textos així com les variacions que es produeixen al llarg del temps i que són fruit de la seva experiència personal i de les circumstàncies sociopolítiques del primer terç del segle XX.

Aquest volum s'estructura en 6 etapes cronològiques. He intentat que cadascuna d'elles tingui la seva pròpia significació des del punt de vista pedagògic.

\section{Etapa I: Les escoles de Guadix (1902-1905)}

Recull els escrits relatius al desenvolupament de l'experiència educativa i social que marcà tan profundament a Poveda. Són molt pocs els escrits en aquesta etapa. Trobem algun text posterior de l'autor que, juntament amb els testimonis dels que van viure i conèixer aquesta experiència, ens permeten intuir què va suposar per a Poveda. Allà va captar -ens ho diu ell mateix- la seva vocació educadora, no només de cara a les persones, a cada persona, sinó també a collectius marginats o no reconeguts per la societat que els envoltava, com el de les coves. Des del principi, l'autor intenta unir dins de la seva pròpia vida i obra, evangelització, educació i compromís social. L'aspiració i la tasca primera de Poveda va consistir en procurar la construcció i posada en marxa d'unes

(2) Hem recuperat aquí l'edició publicada del document, no la nostra edició crítica que és la del text autògraf que va ser un dels criteris adoptats. La diferència, en aquest cas, és significativa. Aquest text es publica després d'un any de lluita i treballs per fer creïble el projecte. També de crítiques sobre l'idealisme del autor. Poveda vol deixar clar que ell ha posat en pràctica una part del projecte i no s'ha limitat a projectar. Es poden comparar els canvis a la pàgina 377 de la nostra edició.

(3) Ana $M^{a}$ Pacheco, $M^{a}$ Isabel Martínez i Ma Pilar Díaz han participat en la redacció de les notes tècniques, aparell crític i notes complementàries. A més, Pacheco ha organitzat un índex temàtic molt interessant. Carmen Cembranos ha col-laborat en el treball de revisió de tota l'Obra feta per les coordinadores de la edició crítica del conjunt d'obres de Pedro Poveda: Ma Dolors Gómez Molleda i Carmen Rita García. 
escoles de qualitat ${ }^{4}$ i treballar per l'apropament de grups socials tan diversos i enfrontats, com els habitants de la ciutat de Guadix i de les coves. Amb la seva marxa dolorosa, es va tancar una etapa de rumors i descrèdit als ambients clericals. Pot ser perquè havia adquirit una popularitat fulgurant fins a ésser nomenat «Fill predilecte de Guadix» per I'Ajuntament d'aquesta localitat i posar-li el seu nom a un carrer. Anys més tard, Poveda recordarà allò que ell denomina «la lliçó de Guadix»: la necessitat d'evitar protagonismes a l'educació, d'actuar més poc a poc, portant la tasca educadora amb discreció i unint forces. Però no cedir davant la calumnia i la injustícia i utilitzar els recursos per a poder defensar-se amb veritat.

\title{
Etapa II: Ensenyar però, per damunt de tot, educar (1906-1911)
}

Reuneix els documents de la primera etapa de Poveda a Covadonga. Es van seleccionar algunes cartes d'un contingut pedagògic significatiu i dos petits opuscles per a nens i joves amb clara finalitat formativa. El darrer escrit revela un canvi en les preocupacions i l'orientació de l'autor. Davant les tendències de la política educativa del país, prepara un projecte per a la formació dels mestres catòlics que volen anar a estudiar a la Escuela Superior del Magisterio, inaugurada el 1909, i, una vegada acabats els seus estudis, desenvolupar llocs rellevants per a la formació i orientació del Magisteri. Malgrat no es va poder dur a bon port per manca de finançament, és molt significatiu que Poveda posés com a condició prèvia per accedir a aquest centre formatiu de futurs líders (Inspectors, professors de les normals, etc.) el que fossin pobres. Una visió certament transformadora! Recordem el seu plantejament:

\begin{abstract}
Los que terminada por completo la carrera, salgan ya destinados como profesores normales o inspectores, seguirán en correspondencia con el centro (...) Escribiremos libros, que más tarde serán los textos de los nuevos profesores de normales; libritos para escuelas y otros trabajos de esta índole (..) Difícil es predecir a dónde vamos; pero si Dios, nos ayuda, la obra tiende en su natural desarrollo a formar con el número de profesores internos, unas Escuelas modelo, donde éstos hagan sus ensayos y practiquen los métodos modernos (...) También podremos ocuparnos en la preparación de maestros para que hagan oposiciones a Escuelas públicas, y en crear una revista que sea la primera en su género y... ¿algo más? Seguramente (Poveda, 1910, 2016, p. 141 i p. 143).
\end{abstract}

\section{Etapa III: Un Pla Nacional de Regeneració educativa (1911-1916)}

És l'etapa més llarga i també la més fecunda, pedagògicament parlant, dels escrits de l'autor. En ella trobem, la majoria dels seus assaigs i projectes pedagògics, i en especial, el projecte global: la Fundació d'una Institució Catòlica d'Ensenyament orientada a la formació inicial i permanent del professorat cristià que es volgués presentar a les oposicions d'escoles públiques (Poveda, 1911a, 2016, p. 191-211)5. Per portar a terme aquest projecte, Poveda idea dues institucions certament originals: les Acadèmies per a la formació inicial del professorat (Poveda, 1911b, 2016, p. 221-245) i els centres pedagògics,

(4) Això s'ha pogut veure en la construcció dels edificis, en la selecció i formació del professorat (Luis Beneito i Josefa Blanco), els materials pedagògics seleccionats, la metodologia utilitzada (inspirada certament en la de Manjón, però amb variants) i el procés per donar resposta a les necessitats que anaven sorgint. Una síntesi de tot això es pot trobar a la presentació d'aquesta etapa (p. 3-23).

(5) Un document clau per a entendre aquest Pla, és el quadern que Poveda omplí sota el títol: Historia de los folletos, (1912c), on expressa amb claredat el perquè planteja un pla tan ambiciós. En aquell quadern havia recollit l'autor les cartes rebudes (amb anotacions i valoracions seves) de persones que havien contestat a l'enviament del projecte principal. Aquesta edició crítica ha inclòs aquest quadern, i també una breu biografia i la significació pedagògica d'aquestes persones, que es pot llegir a les notes complementàries del document. 
per a la formació permanent (Poveda, 1911c, 2016, p. 211-221). L'autor, comença, al mateix temps que difon el seu projecte, a posar en pràctica algunes Acadèmies i es preocupa de donar-les-hi visió, orientació i sentit. Cartes, consells, el Llibre de les fundacions, donen compte de tot aquest treball. L'Acadèmia femenina d'Oviedo va començar a funcionar amb dificultats però amb il|lusió. La de Gijón es va programar però no arribà a posar-se en marxa. Els dos joves mestres que havien de fer-ho, es van trobar amb entrebancs: malalties, falta de suport local, les noces de cadascú, etc. Començaren una revista: Enseñanza Moderna, i també un Centre Pedagògic que durà pocs mesos. La falta de suport per a posar en marxa la ICE (Institución Católica de Enseñanza) i el trasllat de l'autor a Jaén el 1913, animen a Poveda a concretar els seus esforços en l'Obra de les Acadèmies amb dones. Al mateix temps, és professor del seminari, on presentarà un text fonamental: «El estudio de la pedagogía en los seminarios» (Poveda, 1914, 2016, p. 569$590)^{6}$. Els darrers anys d'aquesta etapa es dedica a la formació de les educadores de les Acadèmies i a enfortir la tasca que portaven a terme.

\section{Etapa IV: Qualificació educativa i cultural o cap a una incipient pedagogia univer- sitària (1917-1924)}

En aquesta etapa descobrim una progressiva activitat pedagògica, fruit també de la fundació de la Institució Teresiana. Aquesta modesta associació laïcal de fidels, Pia Unió, dóna, no obstant, força i cohesió a l'Obra de les Acadèmies i recull l'idea germinal de la Institució Catòlica d'Ensenyament (Poveda 1918, 2016, p. 606-608). L'activitat i els escrits de Poveda s'orienten a consolidar organitzativament aquests centres i a obrir espais nous, xarxes diríem avui dia, a través de noves associacions i moviments. La seva missió és donar suport i articular els grups de dones que comencen a tenir una presència pública a la societat a través de la seva professió i de la seva participació als congressos i actes culturals que s'organitzen en aquests anys. Promou l'estudi i la formació intel-lectual de professores i alumnes, i la seva actuació, molt significativa, en fòrums culturals i socials (Poveda, 1920a, 2016, p. 756-759). El trasllat de l'autor a Madrid l'any 1921 facilitarà tota aquesta actuació. Especialment significativa serà la presència de l'Obra al 1r. Congrés Nacional d'Educació Catòlica, el 1924, amb 26 ponències i 56 memòries, a més d'una memòria on s'explicava l'evolució de cada Acadèmia i el seu plantejament pedagògic.

\section{Etapa V: Afirmació de la presència femenina a la Universitat (1925-1930)}

D’aquest període no hem trobat molts textos, més enllà de les cartes. L'autor dedicava una gran part del seu temps a la relació personal i al seguiment de les seves obres. Hi ha una rica correspondència personal que es podrà veure a l'epistolari corresponent a aquesta etapa. És al final d'aquest període, quan Poveda s'interessa de manera especial per donar suport a les joves universitàries, ja que els moviments estudiantils i revolucionaris anaven adquirint una presència significativa. L'autor urgeix a les seves

(6) Possiblement és l'escrit on es pot analitzar millor les fonts pedagògiques manejades per Poveda en aquell moment. La primera part de la seva exposició ofereix una visió de la pedagogia, partint d'una concepció herbartiana, com una ciència aplicada, en estreta relació amb la psicologia i l'ètica. No obstant això, per al desenvolupament complert de la Pedagogia recomana l'estudi al seminari d'un ventall ampli d'autors que pertanyen a diverses corrents pedagògiques; proposa un pla d'estudis i la recomanació de lectures pedagògiques [Veure, en especial les notes d'estudi i complementàries d'aquest document (Poveda, 2016, p. 569-590)]. 
colllaboradores a definir bé el programa sobre la dona i ho fa assenyalant els seus components fonamentals: fe i ciència. Crea un ambient idoni per a la formació de les universitàries: «La casa de la estudiante». I escriu algunes fórmules associatives que cristal-litzaran en l'associació de les estudiantes catòliques.

És cert que, des de feia temps, l'ambient de la residència universitària teresiana de Madrid, afavoria el naixement d'una nova forma de situar-se a la societat. Mercedes Doral, membre de l'equip directiu d'aquesta residència i al mateix temps, estudiant del darrers cursos de la Escuela de Estudios Superiores del Magisterio, ja havia escrit, uns anys abans, aquestes paraules:

Se trata ahora en España de que la mujer entre de lleno a ejercer una acción social e intervenga, aun en la política como uno de los medios de realizar su acción. Es quizá un momento crítico, porque ha de precisarse la dirección que ha de tomar la mujer (...) pero resuélvase como se resuelva la cuestión (...) ¿No estará lo esencial en que para todo se encuentre cultural y moralmente preparada? (Doral, 1919, p. 31).

Poveda estimula aquesta preparació perquè, com diu en un escrit de 1927, «educar a la mujer, aunque sea para la universidad, no es deformarla sino perfeccionarla» (Poveda, 1927, 2016, p. 742).

\section{Etapa VI: Educar en temps de confrontació i violència (1931-1936)}

El canvi polític i social que porta la Segona República, dóna a Poveda una ocasió extraordinària per a revisar la seva proposta i comprovar la viabilitat. Es reafirma en l'opció per la presència de professionals ben preparats a l'ensenyament públic, però això suposa més formació per als que treballen en aquests llocs (Poveda 1935a). El diàleg feciència que havia promogut, manté la seva vigència en aquest moment, però requereix noves formes de situar-se a la realitat professional i social, amb un gran respecte a les lleis i al temps, amb una gran llibertat per a viure i expressar la seva fe fora dels espais escolars (Poveda, 1931, 1935b). En aquells moments difícils, confirma que la seva proposta educativa està inspirada en l'amor i requereix per tant, d'unes relacions càlides i afectuoses, més enllà de qualsevol ideologia (Poveda, 1932). En aquest període intensificarà, a través dels seus escrits, la pedagogia de la no violència, expressada a través de les paraules «mansedumbre» $\mathbf{i}$ «dulzura» (Poveda, 1934b). I dóna suport a les educadores escrivint nombroses cartes i un petit tractat sobre educació «Hablemos de las alumnas» (Poveda, 1934a). El treball universitari s'intensificarà i ho seguirà personalment tal i com queda reflectit en el seu diari de «la casa de la estudiante» (Poveda, 1934-36). Aspira, inclús, a crear un centre d'estudis superiors, que no arribarà a fer-se realitat per la mort de Poveda el 28 de juliol de 1936 (Poveda, 1934c).

Després d'aquest recorregut, em detindré breument en tres punts que considero claus per a comprendre l'aportació pedagògica de Poveda.

\section{Un treball per afavorir moviments que permetin l'articulació d'esforços a favor de l'educació}

El mateix autor ho reconeix en un escrit de l'any 1912.

Aunque mi opinión nada valga, aunque mi escrito no sea tomado en cuenta, y aunque mi llamamiento no encuentre eco en parte alguna, yo diré lo que pienso, escribiré lo que siento y llamaré a la conciencia de todos los católicos para pedirles, que presten la atención que merecen a las cuestiones relacionadas con el movimiento social pedagógico en nuestra patria (Poveda, 1912d, 2016, p. 399). 
Ja hem vist com a Guadix, Poveda procurava fer sempre de la seva actuació educadora una tasca compartida. Anys més tard tornarà a insistir en què la unió d'esforços i la participació són essencials per a portar a terme qualsevol treball i, encara més, si es tracta d'una tasca educativa i social.

A Covadonga, Poveda intenta, des d'una postura crítica i alhora constructiva, contribuir al despertar d'un collectiu emergent: el mestre d'ensenyament primari. Ell ja havia elaborat un projecte global conjunt per a formar i coordinar l'acció dels professionals cristians de l'educació a tots els nivells d'ensenyament al sí d'una societat moderna. Professionals competents, en els nous mètodes pedagògics i capaços de donar resposta des d'un humanisme cristià als problemes educatius i socials del seu temps. Però desitja iniciar el pla, amb la transformació de l'escola primària des dels mateixos educadors i educadores. Escriu articles per animar-los a unir-se al projecte i constituir una Federació de mestres cristians. I afirma: «Ejército poderoso seríamos si la solidaridad fuera patrimonio nuestro» (Poveda, 1912e, 2016, p. 499).

En altres articles insisteix en la mateixa idea. Després de presentar a uns mestres un pla de acció i els beneficis que, de portar-lo a terme trobarien, arriba a dir:

¿Podremos conseguir todo lo dicho? Sí. ¿Cómo? uniéndonos sin prejuicios, con buena voluntad, sin recelos, con esperanza, con ilusión; $y$, sobre todo, no dando por fracasado lo que aún no se ensayó (Poveda, 1912f, 2016, p. 489).

I adverteix, més concretament, la manera pràctica d'avançar cap aquesta unió: perquè «nadie es capaz de calcular lo que darán de sí ocho o diez maestros unidos en pensamientos, deseos y obras» (Poveda 1912g, 2016, p. 495). Poveda inicia així la majoria de les seves propostes, de manera modesta, assequible a qui ha de portar-les a terme.

Una tasca permanent de l'autor va ser la recerca de mitjans per a facilitar el coneixement mutu -i com a conseqüència- la unió de collectius, institucions i persones. Utilitzà per aquesta finalitat tot el que tenia al seu abast: una molt nombrosa correspondència, creació de revistes, organització de trobades, treballs comuns, etc. La comunicació es constituí en un engranatge necessari per a potenciar la vida dels centres creats per Poveda. El professorat havia de disposar d'espais per a compartir els seus avenços i dificultats, els nous mètodes, la situació de l'alumnat. Els pares havien de conèixer els aprenentatges i problemes de les seves filles i donar suggeriments per a la seva educació. Existia una comunicació cordial entre las Acadèmies de les diverses ciutats, una relació cordial amb les Normals, les antigues alumnes, les amistats i els centres culturals i socials de la localitat. Fins i tot, al temps de vacances, no s'aturava el treball col.laboratiu.

\footnotetext{
Reina en el internado de Jaén, en esta época de vacaciones, verdadera fiebre de trabajo, en la preparación de la labor a realizar en las próximas tareas escolares (...) Asimismo, hay un intercambio de impresiones pedagógicas en las cuales se da cuenta de la marcha de la enseñanza, de los frutos obtenidos, defectos hallados, etc. Hechos y datos que están sirviendo para la orientación del próximo curso (Anònim, 1917, p. 335).
}

I és que la seva proposta educativa planteja com a eix fonamental del creixement de totes les persones, el recolzament mutu a través d'unes relacions personals autèntiques.

L'any 1919, Poveda reconeix la conveniència de persones que siguin capaces d'impulsar el moviment cultural necessari perquè l'Obra de les Acadèmies inclogui el professorat de la Normal i de la Inspecció. Planteja un pla molt semblant al que es fa 
actualment des de les xarxes socials. A través de xarxes de persones properes a la Institució Teresiana, anima a les seves colllaboradores a donar a conèixer documents i revistes que puguin interessar a les seves amigues i les animin a formar part del grup. Poc a poc les noves invitarien altres amigues, a través d'un procediment semblant. En un any hi havia professores cooperadores de l'Obra de Poveda a 24 Normals! Aquest mateix esperit li mourà a mantenir unides i articulades a les antigues alumnes, mitjançant una associació professional que els permeti ajudar-se en l'actualització permanent, compartir les seves experiències educatives i viure solidàriament.

\section{La proposta educativa de Poveda i la seva realització a través de dues institucions originals: Les Acadèmies i els Centres pedagògics}

Ja hem assenyalat com el projecte fonamental de Poveda va consistir en la formació inicial i permanent d'educadors i educadores, en especial d'aquells que havien d'integrarse als diversos nivells de l'ensenyament estatal. Educadors inserts en una societat en canvi, disposats a obrir-se a les noves tendències pedagògiques del moment, a dialogar amb la ciència i el progrés, des d'un horitzó de sentit.

I cap a on apuntava aquest horitzó? A assolir una humanitat menys tancada sobre sí mateixa i més oberta als altres. Calia avençar processos d'humanització, des de la tasca quotidiana educativa i cultural, on les persones es reconeixen, s'estimen i donen el millor de sí mateixes. Processos que intentaven integrar a la vida, una fe viscuda, la passió per aprendre i el saber fer i treballar amb altres, bo i donant suport a processos transformadors.

Ara bé, treballar per una educació on les persones fossin el centre del procés educatiu significava per a Poveda acollir-les a totes en la seva originalitat i potencialitat, «tú has de ser siempre tú»-deia- i esforçar-se perquè cadascuna donés el millor de sí mateixa.

L'afirmació de la personalitat per part de l'autor, apareix clarament reflectida en el respecte a la manera d'ésser de cadascú i cadascuna, als seus ritmes de treball, als seus interessos i facilitar la recerca de tot allò que més pot realitzar cada persona, tot buscant al mateix temps allò que és bo per al conjunt de la població. Així ho expressa a la introducció del Reglament de Linares:

\footnotetext{
Bueno para esta población, para estas costumbres, para estos niños, para cada niño. Pues si en los últimos amaneceres de la Pedagogía se prescinde del individuo para considerarlo solo como un ser social, los también modernísimos estudios paidológicos nos demuestran que para la educación no hay ni debe haber niños, sino un niño, cada niño; ser distinto de los demás al que hay que comenzar por conocer y estudiar para aplicarle después la educación que él sea capaz de recibir, aunque se aplique con un fin social, puesto que por la sociedad y para la sociedad ha de ser educado el niño (Poveda, 1916b, 2016, p. 657).
}

Es troba en aquest text la referència clara a una educació personalitzada, que sempre, per a Poveda, necessita articular les característiques individuals de cada persona i la seva dimensió social. Recordem aquella frase molt significativa de l'autor, quan expressava en un projecte com entén l'aprenentatge a l'Acadèmia: «La colectividad y el cambio de impresiones y de iniciativas, hacen surgir estímulos y desarrollar energías que existen» (Poveda, 1911b, 2016, p. 225). I és desprès de posar-se en marxa la dinàmica d'aprenentatge des d'aquest enfocament, quan fa la següent afirmació: «En los alumnos se va acentuando el estímulo y tienen iniciativas que son muy aplaudidas por el Director» (Ibídem, p. 229). 
Poveda vol que es mantingui aquesta capacitat d'iniciativa des de la infantesa, i que, poc a poc, es desenvolupi en les persones una postura crítica davant situacions i fets on es posen en joc valors importants i que reclamen la possessió de criteris clars d'actuació, oberts, al mateix temps, a una capacitat dialogant i discernidora. Aquesta persona així formada devia aprendre a col/laborar i treballar amb altres, perquè els canvis més profunds i transformadors en una societat tenen necessitat del concurs de moltes mans i voluntats. Per això, animava a que la formació del magisteri es portés a terme des d'aquesta doble vessant: prioritat de la persona i dimensió social i solidària, els dos components bàsics de l'educació indissolublement units i que han estat expressades amb força en treballs anteriors sobre l'autor. Un exemple el trobem en aquest text de la professora Ángeles Galino, pionera en l'estudi dels textos pedagògics de Poveda (Galino, 1964). Veiem un dels darrers:

El humanismo pedagógico de Poveda reviste el sentido más obvio de esta expresión, el de ordenar la educación a la persona, entendida ésta en su realidad individual intransferible y en su vertiente social. Educar será una relación de ayuda que en un mismo movimiento aspira a servir al hombre y a la sociedad (Galino, 2000, p. 13).

També descobrim, en els seus projectes o en la presentació de l'educació que ha de presidir les Acadèmies, referències a diverses dimensions de l'educació, des d'una perspectiva integral. Tal com indica Ángela del Valle, «la propuesta de defender una educación integral es una nota propia de la renovación educativa povedana» (Del Valle, 2014, p. 253).

Així doncs, a la reglamentació unificada de les Acadèmies s'hi poden trobar descrites algunes d'aquestes dimensions bàsiques de l'educació:

-la formació moral i religiosa, definida per «una piedad sólida y verdadera al par que sentida, ilustrando a las alumnas en esta materia cuanto es necesario para evitar así la rutina, la superstición y los errores en la misma. El espíritu religioso no se impone, sino que se siente y la formación moral está determinada por los ideales y espíritu cristianos que forman su ambiente» (Poveda, 1924, p. 817).

-la formació intel.lectual, que es cultiva no només per les tasques promogudes des de les classes que es reben en els centres oficials i a la mateixa Acadèmia, sinó «por medio de museos, laboratorios, bibliotecas, conferencias, cursos breves, veladas, etc., enfocando todo ello a despertar la iniciativa de las alumnas y a ponerlas en condiciones de buscar y encontrar el método» (Ibídem, p. 818).

-l'educació física i la higiene perquè «el carácter integral de la formación que se da en los Internados no permite que se descuide en lo más mínimo la naturaleza física de las jóvenes estudiantes. Como en el hogar propio, se vigila cuanto está relacionado con la salud y más sano desarrollo de las alumnas» (Ibídem, p. 819).

-la tasca circumescolar ja que «para la formación social de las alumnas tiene la Institución establecidos en muchos de sus Internados, escuelas dominicales, de adultas, cantinas, roperos, etc.» (Ibídem, p. 819).

-l'orientació post escolar que els permet «el tránsito de su condición de estudiantes a la nueva vida inserta en la sociedad y en la profesión» (Ibídem, p. 819).

La lectura dels textos de Poveda ens confirmen la preocupació educadora de l'autor per expressar el nucli de l'educació i que vindrà confirmada quan, en els darrers anys de la seva vida, expliciti la base del seu sistema educatiu: «Yo os pido un sistema nuevo, un nuevo método, unos procedimientos tan antiguos como nuevos inspirados en el amor» (Poveda, 1932, p. 952).

L'amor -ja ho havia reconegut en un escrit anterior al 1910- es «la fuerza motriz de la humanidad» (Poveda, ant. a 1910. p. 83). Resulta curiós que un pensador contempo- 
rani, Edgard Morin, reivindiqui l'amor al seu programa educatiu orientat cap a l'era planetària:

Donde no hay amor, no hay más que problemas de carrera, de dinero para el docente, de aburrimiento para el alumno. La misión supone evidentemente, fe en la cultura y fe en las posibilidades del espíritu humano. La misión es por tanto elevada y difícil porque supone al mismo tiempo arte, fe y amor (Morin, 2009, p. 123).

En Poveda aquest amor té unes arrels profundes en el cor humà. Perquè el seu humanisme està obert a la transcendència, a Déu, i en la seva forma d'actuar, segueix la via d'un humanisme d'encarnació. Vides humanes a l'estil de Jesús.

Però afavorir unes relacions interpersonals autèntiques suposa la creació de climes $o$ ambients plens d'humanitat, atraients i estimulants, capaços de generar processos de creixement personal i de compromís social. I aquesta va ser una de les aportacions més característiques de la proposta educativa de Pedro Poveda, que es plasma, d'una manera especial, en les institucions educatives creades per ell.

Poveda havia començat -tal com feia normalment- per imaginar-les. Així, les Acadèmies, que eren els centres on es formava el professorat, estan magníficament descrites en el projecte Simulacro Pedagógico. Ell mateix les defineix:

\footnotetext{
Entendemos aquí por Academia, el establecimiento en que se instruye a los que han de consagrarse a la carrera del Magisterio; y desearíamos que tuviesen la amenidad y alegría características de las de Atenas. En estos centros, tal como los imaginamos, es donde los profesores noveles, los que aspiran a serlo, y los encanecidos en el saber y en las lides de la enseñanza, podrán estudiar, practicar, escribir y conferenciar; en ellos podrán robustecerse los vínculos de fraternal amor, echar los cimientos para crear instituciones a favor del profesorado y establecer una verdadera solidaridad. De aquí nacerían competencia, prestigio, representación, recursos y todo lo que necesita el Magisterio (Poveda, 1911b, 2016 [18], p. 225).
}

En aquesta publicació veiem com es despleguen, des d'una iniciativa modesta, començant per poc -al gust de Poveda- els elements clau en la formació d'educadors i en la seva proposta educativa. Podríem aventurar que en "don Plácido», aquell mestre director de l'Acadèmia imaginada, es reflecteix, de manera subconscient, el mateix Poveda. Aquesta petita obra ens descobreix:

- la manera d'iniciar una organització formativa per a educadors: la importància de la visió o del somni sobre allò que desitgem construir, i el compartir-lo poc a poc amb altres. «Son ya tres los profesionales enamorados de la idea: tres que la propagan con entusiasmo» (Ibídem, p. 226).

- la recerca del bé de les persones: «No tratan de llamar la atención. Tratan de hacer bien» (Ibídem, p. 227).

- la necessitat de processos participatius per a desenvolupar processos d'aprenentatge autònom i anar-se apropiant del projecte: «La colectividad y el cambio de impresiones y de iniciativas hacen surgir estímulos y desarrollar energías que existen» (Ibídem, p. 225), la qual cosa es confirma més endavant: «En los alumnos se va acentuando el estímulo y tienen iniciativas que son muy aplaudidas por el director» (Ibídem, p. 227).

- les condicions ambientals per a que en aquesta institució es puguin viure els valors que ens orienten fent que sigui un espai humanitzador:

Este será nuestro centro de reunión: compraremos un piano, organizaremos excursiones, celebraremos veladas literarias y quién sabe si publicaremos algún papelucho que se llame «Eco de la Academia». Total, 
que un loco hace ciento y que ya no son los tres profesores los que sueñan; ya sueña el párroco, los nuevos maestros, los señores que dan clases de Música, etc. Y, más que todos ellos, los veintiocho chicos, cada uno de los cuales, trae cada día un proyecto nuevo (Ibídem, p. 229-230).

- una autoritat que impulsa, respecta, afavoreix la participació i manté la disciplina sense violència.

- la intensitat, per tant, de relacions interpersonals, que afavoreixen l'estudi i la pròpia construcció personal.

- la unió en la formació, de l'estudi i la pràctica.

- la força expansiva del projecte.

- I un indicador clau que convenç: I'entusiasme dels qui han viscut aquesta experiència. L'alegria constituirà un dels elements més destacats no només als escrits de Poveda sinó a les cròniques fetes per persones que s'apropaven a conèixer les Acadèmies.

En realitat, podem trobar molts dels elements claus de la seva proposta educativa, d'una manera més àmpliament recollida, incloent-hi altres aspectes fonamentals del pensament i la pràctica de Poveda, a l'Estudi introductori de Ensayos y Proyectos Pedagógicos.

La formació permanent del professorat es planteja a través d'un altre projecte: el Proyecto Pedagógico Complementario. En aquesta publicació, Poveda enumera els principals problemes de l'ensenyament primari i aposta pel mestre:

Ante todo y sobre todo debemos contar con el profesorado, si queremos que nuestra labor sea provechosa. Sin contar con el maestro, no podemos dar un paso (Poveda, 1911c, 2016, p. 211).

Poveda no ignora, sinó que enumera les circumstàncies en las que viuen els mestres. Són, però, aquestes circumstàncies, les que el mouen a triar el mitjà més adequat per actuar en favor d'ells: afirmar d'aquest collectiu la seva capacitat per a organitzar-se i sortir de la seva situació; per a liderar i treballar pel seu propi desenvolupament i per aconseguir el reconeixement amb formes noves d'actuar. El camí proposat per l'autor serà la creació d'un moviment de mestres que té la seva seu al Centre Pedagògic. Al centre podran reunir-se; realitzar la lectura permanent de llibres i revistes i desenvolupar una petita biblioteca; material que pugui servir d'intercanvi d'impressions entre els mestres i d'estímul per a la seva pràctica. Gradualment, Poveda expressa els canvis que es donen en l'actuació d'aquells professionals, fins arribar a la creació d'un moviment. Es nota molt la influència de l'Escola Nova en les descripcions que fa.

\section{El desenvolupament educatiu i sociocultural d'un col-lectiu emer- gent: les dones}

Tots aquells elements que hem presentat, poden tenir un potencial transformador en temps certament difícils? Intentarem respondre breument a partir d'un col-lectiu concret: les dones. A elles va dedicar Poveda, especialment a partir de 1912, una gran part dels seus esforços educadors.

Ángeles Galino, no dubta en afirmar: «Sin ruido, sin manifestaciones polémicas... convoca a las mujeres a estudiar, a capacitarse y a estar junto al hombre para construir una sociedad más justa» (Galino, 2000, p. 10). És una aposta audaç i certament arriscada. 
Moltes d'aquestes joves que anaven a estudiar magisteri, amb prou feines arribaven a tenir una formació elemental. A l'any 1910 el 60 \% de les dones a Espanya no sabia llegir ni escriure. Calia començar des del principi. Poveda s'embarca, en aquest context, en la formació de futures mestres. Però ha de començar des de la base. Moltes venen a les Acadèmies sense els més elementals rudiments d'instrucció, això sí, amb un desig enorme d'aprendre. Cerca beques, ajuts particulars, i inicia un procés formatiu sense precedents, ja que l’horitzó -jel somni!- que les proposa s'amplia, cada vegada més.

A l'any 1915, quan només hi havien passat 5 anys des del decret que permetia l'accés lliure de la dona a la universitat, Poveda planteja l'oportunitat d'obrir les Acadèmies a joves que desitgin cursar estudis superiors i necessitin, per això triar els estudis de Batxillerat. En un full dedicat a l'orientació dels pares i a l'oferta de les Acadèmies per a les qui desitgen aquest tipus d'estudi es pot llegir:

\footnotetext{
Crece el nivel intelectual de la mujer y las Aulas de las Universidades, Institutos, Escuelas Normales, del Hogar, de Idiomas y otras más, se ven concurridas por muchachas que aspiran a salir de la mediocridad en que hasta ahora ha vivido la mujer, adquiriendo las nobles armas que dan las Ciencias y las Letras, para luchar en la vida sin la tutela a que están sometidas, en un plano inferior al hombre (Poveda, 1915a, 2016, p. 655-656).
}

De manera lenta, en un camí ple d'entrebancs, la dona s'anava obrint pas a les professions i a l'àmbit cultural i social. Ja el març de 1914 Poveda fundà la primera residència universitària per a joves estudiantes que s'obre a Espanya. D'ella i de les que seguiran, anys més tard, diu Ángeles Galino: «Aportan un potencial de energía nunca antes enteramente desarrollado: cultivadoras de los valores de un humanismo integral» (Galino, 2000, p. 11).

En el procés formatiu del dia a dia, amb les seves col-laboradores, i conegut a través de les cartes, Poveda dibuixa, no obstant, un estil de fer les coses i d'ésser, una manera de situar-se en aquesta dinàmica de canvi, que sorprèn per la seva reiteració. L'autor, per experiència, sap el que suposa viure al ull de l'huracà, assetjat a Guadix per les crítiques dels qui no van entendre la seva obra social. I sap que la revolució silenciosa que proposa, en aquesta obra «nova i original», les dones, amb una nova presència pública, cultural, social, familiar i professional, tindran que aconseguir fer «callar la gent insensata i la seva ignorància» (I Pere, 2, 15). L'autor, comentant aquesta frase a les seves colllaboradores, mostrava el camí: això es podria aconseguir fent el bé, essent signe d'una nova humanitat que va trencant, lentament, la barrera de les discriminacions i prejudicis.

\footnotetext{
Haciendo bien a vuestras discípulas, haciendo bien en vuestras clases, haciendo bien en vuestras explicaciones, en vuestros escritos, en los claustros, en las asambleas, en los cargos que se os confíen. (..) Hay que unir a la fe las obras, hay que ejercitarse en hacer bien a todos, en hacer bien lo que hacemos... (Poveda, 1920b, 2016, p. 748-749).
}

Moltes vegades, emperò, Poveda haurà de defensar la seva actuació a favor de les dones. Així l'any 1921 respon a les crítiques de Baldomero Ghiara, sobre la Institució Teresiana, en relació al moviment feminista.

\footnotetext{
Que en punto a feminismo... vamos a la cabeza,.. En las provincias donde hemos establecido internados y en las poblaciones donde tenemos teresianas puede hacerse una estadística de 5 años antes de estar nosotros a 5 años después de tal fecha y se nota un movimiento en la cultura de la mujer extraordinario. Tanto es así que en algunos sitios se nos censura por el exceso de educación intelectual... (Poveda, 1921, 2016 [120], p. 775).
} 
Amb tot, aquestes dones no havien d'utilitzar els procediments que tradicionalment eren emprats pels molts homes a fi d'escalar llocs de poder al treball, per afirmar-se en la societat o per exercir l'autoritat. La vertadera solidaritat a la que invita Poveda suposa trencar esquemes d'un feminisme que copia patrons masculins. Suposa també entendre la pedagogia des d'una nova concepció. «Vamos a desterrar la palabra mando» (Poveda, 1935b, 2005, p. 1233). "Yo, que no dudo nunca del buen éxito, cuando depende solamente de las alumnas su consecución» (Poveda, 1916b, 2016, [98] p. 639). Paraules que, avui dia, resulten provocadores per la seva senzillesa. Poveda reconeix que la tasca no és pas fàcil. Deixar el protagonisme als altres, afavorir el treball en equip, facilitar la unió d'esforços, educar sense crispació, amb afabilitat i mansuetud, entregar temps i vida sense càlcul i no pretendre triomfs ni refusar fracassos, des d'una actuació serena, suposa uns procediments «tan nuevos como antiguos inspirados en el amor» (Poveda, 1932, 2016, p. 952).

El camí cap una presència pública en la societat suposarà una formació intel.lectual seriosa que asseguri la qualitat educativa i cultural; la recerca de persones que donin suport a aquest moviment en la tasca d'aconseguir una presència pública en centres de I'Estat, en llocs de responsabilitat, en el terreny polític, social, cultural y pedagògic (Flecha, 2014, p. 313-353). Els darrers anys de la seva vida els dedicà Poveda a treballar intensament en la formació universitària. Així va crear diverses associacions amb aquesta finalitat, que quan arriba la Segona República cristal-litzen en la Lliga Femenina d'Orientació i Cultura. L'anàlisi dels llistats d'associades i adscrites a la Lliga, resulta molt significatiu. Entre 1932 i 1936, figuren 175 graduades i estudiantes universitàries, que pertanyen a diverses carreres. I en la seva seu, «la casa de l'estudiant», pot apreciar-se com es comença a desenvolupar un projecte que aspirava a convertir-se en un centre d'educació superior femení.

\section{Referències}

Anònim (1917) «Labor teresiana», Boletín de las Academias Teresianas. 2a època. 1 d'agost. Núm. 21, p. 333-335.

Arteaga, C. (1921) «Certamen literario para el alumnado de las cuatro Normales catalanas», Documentación complementaria [179], a Bartolomé, Margarita (Coord.) et al. (2016) Pedro Poveda. Obras II. Ensayos y Proyectos Pedagógicos. Volum segon de l'edició crítica de les Obres de Pedro Poveda coordinades per Ma Dolores Gómez Molleda i Carmen Rita García. Madrid, Narcea, p. 1055-1058.

Bartolomé, $M$.

- (1973) Un pensamiento para la acción. El problema educativo en los textos de Pedro Poveda. Barcelona, ACIT. Text policopiat.

- (1974) «Poveda y la Pedagogía ambiental». Eidos, núm. 39-40, p. 111-134.

- (1979) «Los valores en los distintos humanismos y su proyección en la experiencia educativa» a IEPS. Educación y valores. Sobre el sentido de la acción educativa en nuestro tiempo. Madrid, Narcea, p. 39-164.

- (1981) «Los valores en la investigación educativa», a Cembranos, Carmen i Bartolomé, Margarita. Estudios y experiencias sobre educación en valores. Madrid, Narcea, p. 89-113.

- (1988) «El cambio de finalidades en la educación. Cuestionamiento desde la reflexión pedagógica de Poveda». Fundación Institución Teresiana Pedro 
Poveda. Volumen-homenaje cincuentenario. 1936-1986. Madrid, Narcea, p. 432-457 (ponència).

- (1998) «Un nuevo educador para una sociedad nueva» al Congreso de Pedagogía. Pedro Poveda educador. Atreverse a educar. Madrid, Narcea, p. 79111 (conferència).

- (2008) Pedro Poveda. En el corazón del mundo. Barcelona, Centre de Pastoral Litúrgica.

- (2012) «Alrededor de un proyecto ¿Otra educación es posible?» al Congreso EDUCA2011. Otra educación es posible. Madrid, Narcea, p. 17-45 (conferència inaugural).

- (2015) «Desde Poveda. Una hoja de ruta para tiempos inciertos», a González Garmendía, Ma. J. ¿Qué educación en esta sociedad? Salamanca, Universidad Pontificia de Salamanca, Cátedra Pedro Poveda, p. 89-134.

- (Coord.) et al. (2016) Pedro Poveda. Obras II. Ensayos y Proyectos Pedagógicos. Edició crítica i estudi a càrrec de Margarita Bartolomé Pina amb la colllaboració d’Ana Ma. Pacheco Martínez, Ma. Pilar Díaz Palacio i Ma. Isabel Martínez Mercado. Volumen II de l'edició crítica de les Obras de Pedro Poveda, coordinades per Ma Dolores Gómez Molleda i Carmen Rita García. Madrid, Narcea.

Costa, J. (1889) Escuela y despensa. El actual problema de España y la liga nacional, en Maestro, escuela y patria. Madrid, Biblioteca Costa, 1916. Disponible a: http://www.cervantesvirtual.com/obra-visor/maestro-escuela-y-patria-notaspedagogicas--0/html/fefa2e40-82b1-11df-acc7-002185ce6064_12.htm\#12

Del Valle, Á. (2014) «Una propuesta educativa en las primeras décadas del siglo veinte». A Rosique, Francisca (Ed.) Historia de la Institución Teresiana (1911-1936). Madrid, Silex, p. 201-261.

Doral, M. (1919) «La Institución Teresiana».Voluntad, núm. 23, p. 29-32.

Flecha, C. (2014) «Un feminismo católico con perfiles propios», a Rosique, Francisca (Ed.) Historia de la Institución Teresiana. Madrid, Sílex, p. 313-355.

Galino, Á. (1964) Pedro Poveda. Itinerario pedagógico. Madrid, Consejo Superior de Investigaciones Científicas.

Galino, Á. (1968) «Pedro Poveda Castroverde» a Galino, Á. (Dir.) Textos pedagógicos hispanoamericanos. Madrid, Iter Ediciones, p. 1471-1506.

Galino, Á. (2000) «Prólogo» a Galino, Á. (Coord.) Humanismo pedagógico de Pedro Poveda. Algunas dimensiones. Madrid, Narcea, p. 7-14.

Morin, E. (2009) Educar en la era planetaria. Barcelona, Gedisa.

Ortega y Gasset, J. (1910) «La pedagogía social como programa político», Conferència impartida el 12 de març de 1910 a Bilbao, a Ortega y Gasset, José. Obras completas. Madrid, Occidente, 1946, vol. I, p. 494-513.

Poveda, P. (1903) «Solicitud de subvención Pública», a Bartolomé Margarita (Coord. et al.). (2016) Pedro Poveda Obras. Vol. II Ensayos y Proyectos pedagógicos, edición crítica. Madrid, Narcea, [5] p. 36-38.

- (1904) «Escuelas del Sagrado Corazón de Jesús establecidas en las Cuevas de la Ermita Nueva. V. Edificios y material», a Ensayos. Obra cit. [6] p. 45-46.

— (Ant. a 1910) «El amor, fuerza motriz», a Ensayos. Obra cit. [10] p. 83-84. 
- (1910) «Proyecto y presupuesto para un Internado de la Escuela Superior», a Ensayos. Obra cit. [13] p. 136-146.

- (1911a) «Proyecto Pedagógico para una Institución Católica de Enseñanza» a Ensayos. Obra cit, [16] p. 191-211.

- (1911b) «Simulacro pedagógico», a Ensayos. Obra cit. [18], p. 221-245.

- (1911c) «Proyecto Pedagógico complementario», a Ensayos. Obra cit. [17], p. 211-221.

- (1912a) «Los temas del día», a Ensayos. Obra cit. [60], p. 506-509.

- (1912b) «Histórico», a Poveda, P. (1989) Folletos. Ed. Facsímil. Madrid, Public. Arxiu de la Institució Teresiana, p. 175-187.

- (1912c) «Historia de los folletos», a Ensayos. Obra cit. [53], p. 405-480.

- (1912d) «Aunque mi opinión nada valga», a Ensayos. Obra cit. [51], p. 399-401.

- (1912e) «Es el momento oportuno», a Ensayos. Obra cit. [58], p. 496-499.

- (1912f) «Proyecto sencillo de gran transcendencia», a Ensayos. Obra cit. [55], p. 487-490.

- (1912g) «La unión de los maestros», a Ensayos. Obra cit. [100], p. 657-664.

- (1914) «El estudio de la pedagogía en los seminarios», a Ensayos. Obra cit. [81] p. 569-590.

- (1915a) «Estudios de Bachillerato para la mujer. Reglamento de la Academia Internado de Santa Teresa de Jaén. 1916» a Ensayos. Obra cit. [99], p. 655-656.

- (1915b) «La vida de familia en los internados», a Ensayos. Obra cit. [98], p. 633643.

- (1916a) «La vida de familia en los internados. Normas para el internado de Jaén», a Ensayos. Obra cit. [98], p. 633-643.

- (1916b) «Academia de Santa Teresa de Jesús de Linares», a Ensayos. Obra cit. [100], p. 657-664.

- (1918) «Sobre los fines y medios educativos de la Institución Teresiana», a Ensayos. Obra cit. [104], p. 606-608.

- (1920a) «Consejos sobre el estudio» a Ensayos. Obra cit. [115], p. 756-759.

- (1920b) «A los que han gustado cuan suave es el Señor. Las cooperadoras técnicas» a Ensayos. Obra cit. [114], p. 746-751.

- (1921) «En punto a feminismo figuramos en la avanzada», a Ensayos. Obra cit. [120], p. 774-775.

- (1924) «Reglamentación unificada de las Academias», a Ensayos. Obra cit. [129], p. 815-824.

- (1927) «Preparación para la universidad» a Poveda, Pedro, Creí, por esto hablé. Vol. I. de la edic. crítica: Pedro Poveda. Obras [235]. Madrid, Narcea, p. 741-742.

- (1931) «La educación en la fe, un deber primordial», a Ensayos. Obra cit. [149], p. 936-937.

- (1932) «Os pido un sistema nuevo», a Ensayos. Obra cit. [154], p. 951-952.

- (1934a) «Hablemos de las alumnas», a Ensayos. Obra cit. [159], p. 964-978

- (1934b) «Actitud ante la confrontación», a Ensayos. Obra cit. [172], p. 10241027. 
- (1934c) «Hacia un Centro de Educación Superior Femenino», a Ensayos, Obra cit. [165] p. 1003-1004.

- (1934-1936) «El diario de la Casa de la estudiante», a Ensayos. Obra cit. [164] p. 991-1002.

- (1935a) «La presencia en la enseñanza pública», a Ensayos. Obra cit. [173] p. 1030-1031.

- (1935b) Sé austero para ti, benigno para los demás, a Creí por esto hablé. Vol. I. Obra cit. [479], p. 1232-1233.

Sela, Aniceto (1910) La educación nacional. Hechos e ideas. Madrid, Librería general de Victoriano Suarez. 


\section{Pedro Poveda: ensayos y proyectos pedagógicos}

Resumen: Presentamos la edición crítica de las obras pedagógicas de Pedro Poveda (1874-1936), recientemente publicadas. Ofrecemos unos ejes fundamentales de su trabajo pedagógico: A) Su fe en la educación como un instrumento extraordinariamente importante para el cambio social y educativo, en los periodos críticos de cualquier sociedad. B) La unión de esfuerzos, la capacidad de responder a los retos del momento con creatividad y realismo, y desde movimientos y grupos, unidos por un proyecto común: la formación inicial y permanente de educadores, en especial la de aquellos que se orientaban al ejercicio profesional en centros de titularidad pública. C) Su propuesta educativa, que hunde sus raíces en un humanismo cristiano, atrayente y abierto, y pretende potenciar el desarrollo de la persona, desde ambientes «cargados de humanidad», densos en relaciones interpersonales, favorecedores del estudio y la práctica, el trabajo autónomo, una vida plena de sentido y orientada al compromiso social. D) La implicación de Poveda en la formación de un colectivo emergente: las mujeres, que, desde su vocación pedagógica, deseaban articular la vida de fe y el progreso cultural y científico; el compromiso profesional y la apertura al espacio público de una sociedad en cambio, en la que estrenaban un nuevo rol y un nuevo estilo de vida.

Palabras clave: Pedro Poveda, movimientos pedagógicos, formación del profesorado, enseñanza pública, humanismo cristiano, ambiente educativo, amor pedagógico, fe-ciencia, educación integral, formación de la mujer, compromiso social.

\section{Pedro Poveda : essais et projets pédagogiques}

Résumé: Dans cet article, nous présentons l'édition critique des œuvres pédagogiques de Pedro Poveda (1874-1936), publiées récemment, et proposons quelques axes fondamentaux de son travail pédagogique, entre autres : a) sa foi dans l'éducation en tant qu'outil crucial pour le changement social et éducatif dans les périodes critiques de toute société ; b) l'union des efforts et la capacité de relever les défis du moment en faisant preuve de créativité et de réalisme, à travers des mouvements et des groupes unis par un projet commun: la formation initiale et permanente d'éducateurs et éducatrices, notamment ceux qui envisageaient d'exercer la profession dans des établissements publics; c) sa proposition éducative, profondément ancrée dans un humanisme chrétien, attrayant et ouvert, qui visait à encourager le développement de la personne en favorisant les environnements riches en valeurs humaines et en relations interpersonnelles, propices à l'étude, à l'autonomie dans le travail, à une vie pleine de sens et orientée vers l'engagement social ; et d) l'implication de Poveda dans la formation d'un collectif émergent, celui des femmes, qui, fortes de leur vocation pédagogique, entendaient concilier la vie avec la foi et le progrès scientifique et culturel, l'engagement professionnel et l'ouverture sur l'espace public d'une société changeante, entrant sur scène avec un nouveau rôle et un nouveau style.

Mots clés: Pedro Poveda, mouvements pédagogiques, formation des enseignants, enseignement public, humanisme chrétien, environnement éducatif, amour pédagogique, foi-science, éducation intégrale, formation des femmes, engagement social.

\section{Pedro Poveda: essays and pedagogical projects}

Abstract: This volume reviews the Critical Edition of the recently published pedagogical works of Pedro Poveda (1874-1936). We present four of the essential themes of his writings: first, his faith in education as an extraordinarily important tool for social and educational change in critical periods of any society; second, his conviction that the challenges of the day could be met with creativity and realism from movements and groups united by a common project (namely, the initial and continuous training of educators, especially those who chose to work in state-financed schools); third, his engaging educational proposal which, both open and deeply rooted in Christian humanism at the same time, sought to strengthen individual development by humanizing environments with interpersonal relationships which could benefit study, autonomous working and a meaningful life aimed at social commitment; and fourth, his involvement in the training of the emerging community of women, whose pedagogical calling was to structure life with faith and scientific and cultural progress, defend professional commitment and help develop a changing society with its new role and style.

Keywords: Pedro Poveda, pedagogical movements, teacher training, teaching in state-funded schools, Christian humanism, educational environment, pedagogical love, faith-science, holistic education, teaching of women, social commitment. 